\section{Effects of the topical treatment with \\ NSAIDs on corneal \\ sensitivity and \\ ocular surface of \\ Sjögren's syndrome patients}

P Aragona, A Stilo, F Ferreri and M Mobrici

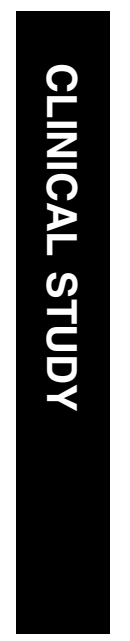

Eye (2005) 19, 535-539. doi:10.1038/sj.eye.6701537

Published online 21 May 2004

Keywords: indomethacin; diclofenac; corneal sensitivity; corneal epithelial defects; Sjögren's syndrome

\section{Introduction}

Sjögren's syndrome (SS) is an autoimmune disease characterized by lymphocytic infiltration of exocrine glands and mucosae. ${ }^{1,2}$ The ocular surface shows in both conjunctiva and lacrimal glands T-cell infiltration and upregulation of expression in markers of immune activation. ${ }^{3}$ Furthermore, it was shown that patients with dry eye in course of autoimmune disorders may present a reduced corneal sensitivity. ${ }^{4,5}$

It was shown that the topical antiinflammatory treatment of dry eye patients brought to a significant reduction of the numbers of activated lymphocytes within the conjunctiva, so demonstrating the potential usefulness of an anti-inflammatory treatment for dry eye. ${ }^{6}$

The treatment of ocular surface inflammation can be helpful to improve symptoms of ocular discomfort in patients with SS. Nonsteriodal anti-inflammatory drugs (NSAIDs) could be considered a good alternative to steroids in order to avoid all the complications of steroidal therapy in the treatment of patients with chronic diseases such as SS. Several reports indicate that NSAIDs might have an influence on corneal sensitivity. ${ }^{7-9}$ Such effect might interfere with corneal epithelium healing in patients with epithelial defects. Previous reports showed, sporadically, the possibility of corneal melting
Department of Surgical Science

Section of Ophthalmology Messina, Italy

Correspondence: P Aragona Viale Boccetta, 70 Messina I-98122, Italy Tel: + 39090343184 Fax: + 390902924819

E-mail: paragona@

unime.it

Received: 11 June 2003 Accepted in revised form: 20 February 2004 Published online: 21 May 2004

Financial interest: none Industry sponsorship: none University of Messina 
and perforation, following the use of NSAIDs after surgery in patients both with or without systemic diseases such as rheumatoid arthritis, SS, and rosacea. ${ }^{10-13}$

The aim of this paper is to evaluate the effects of two commercially available NSAIDs on corneal sensitivity and corneal epithelium in SS patients.

\section{Materials and methods}

\section{Patients population}

In all, 20 patients (19 female and one male, age range 35-65-years-old) affected by SS (eight primary and 12 secondary), diagnosed according to the classification criteria proposed by the American-European Consensus Group, ${ }^{14}$ were randomly divided in two groups and assigned to treatment with instillation of three drops / day of topical NSAIDs: Group 1, 10 patients (10 females; mean age \pm SD $53.9 \pm 8.9)$, treated with $0.1 \%$ indomethacin (Indocollirio ${ }^{\circledR}$, Bausch \& Lomb Oftal, Catania, Italy); group 2, 10 patients (nine female, one male; $54 \pm 7.2$ ), treated with $0.1 \%$ diclofenac (Voltaren $\mathrm{Ofta}^{\circledR}$, Novartis Farma, Hettlingen, Switzerland).

\section{Study design}

Controlled, single-blind, parallel, clinical study.

\section{Inclusion criteria}

Patients able and willing to participate to the study signed an informed consent. They were selected from patients referring to the Ocular Surface Diseases Section of the Ophthalmology Section of the Department of Surgical specialties of the University of Messina. The patients included in the study had a corneal epithelial defects with a score of at least $2+$ according to Lemp, ${ }^{15}$ evaluated with fluorescein vital stain, and a stable disease and general therapy for at least 1 month. They accepted not to use general NSAIDs for all the period of the study. Patients were allowed to continue their therapy with tear substitutes.

\section{Exclusion criteria}

Corneal epithelial defects with a score minor than $2+$ according to Lemp; unstable general disease or changes in systemic therapy within one month. Concurrent diseases such as diabetes, ocular herpes (even past), contact lens wear, use of drugs such as beta-blockers, calcium antagonists, benzodiazepines, antidepressants, anti-histaminics, hormones, and any ocular therapy other than tear substitutes.

\section{Main outcome measures}

Patients were examined in a masked manner with respect to their treatment. Primary parameter was corneal sensitivity measured by the Cochet-Bonnet aesthesiometer (Luneau Ophtalmologie, Chartres, France) (mm of filament). Secondary parameters were ocular discomfort symptoms (burning, itching, foreign body sensation, dryness, mucous discharge,

photophobia) evaluated according to a scoring system from 0 (absent) to 3 (severe): a global score, obtained adding the score of each symptom, was considered for the evaluation of ocular discomfort; BUT (sec); corneal fluorescein vital staining (score 0-15).

The evaluation of parameters was performed before treatment (T0) and after 15 (T15), 30 (T30) days of treatment. A follow-up visit was also performed 7 days after the discontinuation of therapy (T7FU), in both eyes.

\section{Statistical analysis}

For statistical analysis only the right eye values were considered. The Student's $t$-test for parametrical data and Mann-Whitney $U$ test for nonparametrical data were used.

\section{Results}

The results are summarized in Tables 1-4.

At baseline, corneal sensitivity was $57 \pm 4.2$ in group 1 and $55.5 \pm 9.3$ in group 2; corneal fluorescein score was $3.5 \pm 1.8$ in group 1 and $3.6 \pm 1.7$ in group 2 ; the symptoms score was $7.5 \pm 3$ in group 1 and $6.7 \pm 1.7$ in group 2; the BUT was $2.2 \pm 0.9$ in group 1 and $2.1 \pm 0.7$ in group 2.

After 15 days there was, in both groups, a statistically significant reduction of the symptoms score $(4.8 \pm 1$ in

Table 1 Results (mean \pm SD) of corneal sensitivity (mm)

\begin{tabular}{lcccc}
\hline & T0 & T15 & T30 & T7 FU \\
\hline $0.1 \%$ indomethacin & $57.0 \pm 4.2$ & $54.0 \pm 9.7$ & $52.0 \pm 6.3^{* * * *}$ & $53.0 \pm 5.4$ \\
$0.1 \%$ diclofenac & $55.5 \pm 9.3$ & $57.0 \pm 2.6$ & $43.5 \pm 8.5^{*}$ & $48.0 \pm 7.1$ \\
\hline${ }^{*} P<0.04$ vs baseline; ${ }^{* *} P=0.01$ vs diclofenac group at the same visit.
\end{tabular}

Table 2 Results (mean \pm SD) of corneal fluorescein staining (score)

\begin{tabular}{lcccc}
\hline & T0 & T15 & T30 & T7 FU \\
\hline $0.1 \%$ indomethacin & $3.5 \pm 1.8$ & $2.7 \pm 2.7$ & $3.0 \pm 2.3$ & $2.5 \pm 1.8^{*}$ \\
$0.1 \%$ diclofenac & $3.6 \pm 1.7$ & $4.3 \pm 1.2$ & $4.6 \pm 1.1$ & $4.1 \pm 1.0$ \\
\hline
\end{tabular}

${ }^{*} P=0.02$ vs diclofenac group at the same visit. 
Table 3 Results (mean \pm SD) of ocular discomfort symptoms score

\begin{tabular}{lcccc}
\hline & T0 & T15 & T30 & T7 FU \\
\hline $0.1 \%$ indomethacin & $7.5 \pm 3.0$ & $4.8 \pm 1.0^{*}$ & $3.3 \pm 12.2^{*}$ & $4.3 \pm 1.2^{*}$ \\
$0.1 \%$ diclofenac & $6.7 \pm 1.7$ & $5.4 \pm 0.8^{* *}$ & $3.2 \pm 1.6^{* *}$ & $4.1 \pm 1.4^{* *}$ \\
\hline
\end{tabular}

${ }^{*} P<0.01$ vs baseline; ${ }^{* *} P<0.05$ vs baseline.

Table 4 Results (mean \pm SD) of break up time (s)

\begin{tabular}{lcccc}
\hline & T0 & T15 & T30 & T7 FU \\
\hline $0.1 \%$ indomethacin & $2.2 \pm 0.9$ & $2.0 \pm 0.9$ & $2.3 \pm 0.7$ & $2.4 \pm 0.8$ \\
$0.1 \%$ diclofenac & $2.1 \pm 0.7$ & $2.1 \pm 0.9$ & $2.0 \pm 1.0$ & $2.5 \pm 0.8$ \\
\hline
\end{tabular}

group 1 and $5.4 \pm 0.8$ in group $2, P=0.01$ and $P=0.004$ vs baseline respectively), which remained up to the end of the study.

At day 30, a statistically significant reduction of corneal sensitivity was observed in both groups $(52 \pm 6.3$ in group 1 and $43.5 \pm 85$ in group $2, P=0.04$ and $P=0.005$ vs baseline respectively), although the reduction observed in group 2 was statistically significantly higher than that of group $1(P=0.01)$.

At 7 days after the discontinuation of therapy corneal sensitivity did not show statistically significant variations (Figure 1).

A statistically significant difference between the two groups was present for corneal fluorescein stain (score $2.5 \pm 1.8$ for group 1 and $4.1 \pm 1$ for group $2 ; P=0.02$ )

(Figure 2).

\section{Discussion}

This is the first trial aimed to study the effects of topical NSAIDs treatment onto the ocular surface of SS patients. Our findings showed that both treatments with $0.1 \%$ indomethacin and $0.1 \%$ diclofenac brought to an

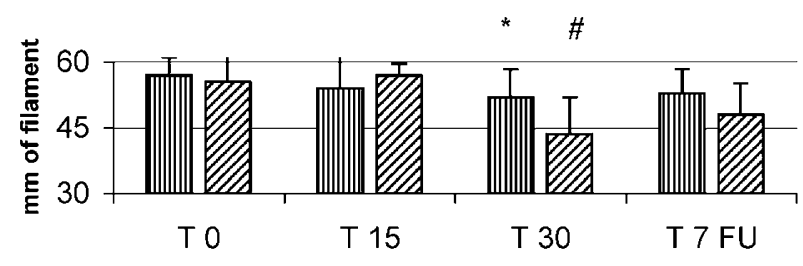

四 $0.1 \%$ Indomethacin $\square 0.1 \%$ Diclofenac

Figure 1 Corneal sensitivity before drug administration (T0), after 15 (T15) and 30 (T30) days of treatment, and 7 days of follow-up (T7FU) after the suspension of the treatment. ${ }^{*} P=0.04$ vs baseline; ${ }^{* *} P=0.005$ vs baseline and $P=0.01$ vs indomethacin group at the same visit.

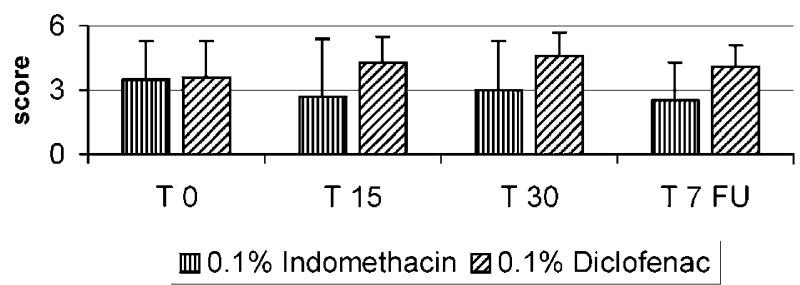

Figure 2 Corneal fluorescein stain score before drug administration (T0), after 15 (T15) and 30 (T30) days of treatment, and 7 days of follow-up (T7FU) after the suspension of the treatment. ${ }^{*} P=0.02$ between the two groups at the 7-day follow-up visit.

amelioration of symptoms of ocular discomfort accompanied, after 1 month of treatment by a reduction of corneal sensitivity. Diclofenac determined a statistically significant greater impairment of corneal sensitivity than indomethacin. No intragroup statistically significant deterioration of corneal epithelium was observed in both groups. However, the indomethacintreated group showed a trend towards an improvement of corneal conditions, while in the diclofenac-treated group, the corneal conditions had a trend towards deterioration. Furthermore, at the visit carried out 7 days after the discontinuation of therapy, the diclofenactreated group showed a statistically significantly higher corneal score if compared to the indomethacin-treated group.

Topical NSAIDs are nowadays widely used for the treatment of several ocular conditions, including corneal traumatic and inflammatory diseases.

Previous reports showed that ophthalmic NSAIDs were useful to decrease pain in patients with corneal abrasions who must return to work immediately, particularly where potential opioid-induced sedation was intolerable. $^{16}$

Indomethacin combined with gentamycin eyedrops was statistically significantly more effective and well tolerated, than gentamycin alone, in reducing the pain and discomfort associated with traumatic corneal abrasion. ${ }^{17}$

It was highlighted the efficacy of indomethacin as a pain reducer for acute corneal diseases and suggested that the medication could act on the corneal nociceptors. $^{18}$

Topical indomethacin $0.1 \%$ solution was as effective as topical dexamethasone phosphate $0.1 \%$ solution for the treatment of inflamed pterygium and pinguecula and, therefore, it was suggested as an effective treatment for these conditions. ${ }^{19}$

Topical $0.1 \%$ indomethacin solution helped control the pain induced by excimer laser photoablation of the cornea without any detrimental effect to the corneal epithelial wound healing. ${ }^{20}$ 
Indomethacin, diclofenac, and flurbiprofen, as well as the calcium antagonist diltiazem, were able to diminish the responsiveness of corneal polymodal nociceptors to chemical stimuli. This appeared to be caused, in part, by a direct effect of these drugs on the excitability of polymodal nerve endings, but also by an inhibitory action of NSAIDs on the formation of cyclooxygenase products such as prostaglandins, thus reducing the enhanced responsiveness of nociceptors caused by local release of arachidonic acid metabolites from injured cells. $^{21,22}$

Despite their many advantages, NSAIDs seem to delay early corneal wound healing and re-epithelialization. ${ }^{23}$ Furthermore, although infrequent, the use of NSAIDs may predispose patients with conditions such as autoimmune disease, rosacea, or dry eyes, to ocular surface alterations. Among these, the most commonly reported adverse effects are symptoms of stinging and irritation. Superficial punctate keratitis is another wellknown side effect. Corneal infiltrates and melting were also reported with NSAID use. ${ }^{10,12,24,25}$ A higher incidence of persistent epithelial defects associated with diclofenac use after penetrating keratoplasty was reported. $^{26}$

Corneal sensitivity was shown to be of great importance for maintaining a healthy corneal epithelium. ${ }^{27}$ In fact, in various types of corneal diseases such as herpetic keratitis, corneal sensitivity is reduced and this often is associated with epithelial defects in those anaesthetized corneas. ${ }^{28,29}$ It was observed that NSAIDs may have an effect on corneal sensitivity. A significant decrease of corneal sensation in normal eyes was observed when multiple drops of $0.1 \%$ diclofenac were used. ${ }^{7-9,30}$

In conclusion, our results indicate that NSAIDs can be useful in resolving symptoms of ocular discomfort in SS syndrome patients. However, they should be used with caution and under close monitoring, and the treatment should be promptly discontinued if corneal epithelial defects develop or worsen during treatment.

\section{References}

1 Brignole F, Pisella PJ, Goldschild M, De Saint Jean M, Goguel A, Baudouin C. Flow cytometric analysis of inflammatory markers in conjunctival epithelial cells of patients with dry eyes. Invest Ophthalmol Vis Sci 2000; 41: 1356-1363.

2 Jones DT, Monroy D, Ji Z, Atherton SS, Pflugfelder SC. Sjögren's syndrome: cytokine and Epstein-Barr viral gene expression within the conjunctival epithelium. Invest Ophthalmol Vis Sci 1994; 35: 3493-3504.

3 Stern ME, Gao J, Schwalb TA, Ngo M, Tieu DD, Chan CC et al. Conjunctival T-cell subpopulations in Sjögren's and
non-Sjögren's patients with dry eye. Invest Ophthalmol Vis Sci 2002; 43: 2609-2614.

4 Aragona P, Romeo GF, Oteri F, Giordano G, Santamaria S, Ferreri G. Correlazioni tra sensibilità corneale e funzione lacrimale in soggetti affetti da connettiviti. Boll Ocul 1994; 73 (Suppl. 1): 115-120.

5 Rosenberg ME, Tervo TM, Immonen IJ, Muller LJ, Gronhagen-Riska C, Vesaluoma MH. Corneal structure and sensitivity in type 1 diabetes mellitus. Invest Ophthalmol Vis Sci 2000; 41: 2915-2921.

6 Kunert KS, Tisdale AS, Stern ME, Smith JA, Gipson IK. Analysis of topical cyclosporine treatment of patients with dry eye syndrome: effect on conjunctival lymphocytes. Arch Ophthalmol 2000; 118: 1489-1496.

7 Aragona P, Tripodi G, Spinella R, Lagana E, Ferreri G. The effects of the topical administration of non-steroidal antiinflammatory drugs on corneal epithelium and corneal sensitivity in normal subjects. Eye 2000; 14 (Part 2): 206-210.

8 Seitz B, Sorken K, LaBree LD, Garbus JJ, McDonnell PJ. Corneal sensitivity and burning sensation. Comparing topical ketorolac and diclofenac. Arch Ophthalmol 1996; 114: 921-924.

9 Szerenyi K, Sorken K, Garbus JJ, Lee M, McDonnell PJ. Decrease in normal human corneal sensitivity with topical diclofenac sodium. Am J Ophthalmol 1994; 118: 312-315.

10 Hsu JK, Johnston WT, Read RW, McDonnell PJ, Pangalinan $\mathrm{R}$, Rao $\mathrm{N}$ et al. Histopathology of corneal melting associated with diclofenac use after refractive surgery. J Cataract Refract Surg 2003; 29: 250-256.

11 Flach AJ. Corneal melts associated with topically applied nonsteroidal anti-inflammatory drugs. Trans Am Ophthalmol Soc 2001; 99: 205-210.

12 Guidera AC, Luchs JI, Udell IJ. Keratitis, ulceration, and perforation associated with topical nonsteroidal antiinflammatory drugs. Ophthalmology 2001; 108: 936-944.

13 Lin JC, Rapuano CJ, Laibson PR, Eagle Jr RC, Cohen EJ. Corneal melting associated with use of topical nonsteroidal anti-inflammatory drugs after ocular surgery. Arch Ophthalmol 2000; 118: 1129-1132.

14 Vitali C, Bombardieri S, Jonsson R, Moutsopoulos HM, Alexander EL, Carsons SE et al. Classification criteria for Sjogren's syndrome: a revised version of the European criteria proposed by the American-European Consensus Group. Ann Rheum Dis. 2002; 61(6): 554-558.

15 Lemp MA. Report of the National Eye Institute/Industry workshop on clinical trials in dry eyes. CLAO J 1995; 21: 221-232.

16 Weaver CS, Terrell KM. Evidence-based emergency medicine. Update: do ophthalmic nonsteroidal antiinflammatory drugs reduce the pain associated with simple corneal abrasion without delaying healing? Ann Emerg Med 2003; 41: 134-140.

17 Alberti MM, Bouat CG, Allaire CM, Trinquand CJ. Combined indomethacin/gentamicin eyedrops to reduce pain after traumatic corneal abrasion. Eur J Ophthalmol 2001; 11: 233-239.

18 Patrone G, Sacca SC, Macri A, Rolando M. Evaluation of the analgesic effect of 0.1 indomethacin solution on corneal abrasions. Ophthalmologica 1999; 213: 350-354.

19 Frucht-Pery J, Siganos CS, Solomon A, Shvartzenberg T, Richard C, Trinquand C. Topical indomethacin solution versus dexamethasone solution for treatment of inflamed pterygium and pinguecula: a prospective randomized clinical study. Am J Ophthalmol 1999; 127: 148-152. 
20 Assouline M, Renard G, Arne JL, David T, Lasmolles C, Malecaze $\mathrm{F}$ et al. A prospective randomized trial of topical soluble $0.1 \%$ indomethacin versus $0.1 \%$ diclofenac versus placebo for the control of pain following excimer laser photorefractive keratectomy. Ophthalmic Surg Lasers 1998; 29: 365-374.

21 Phillips AF, Hayashi S, Seitz B, Wee WR, McDonnell PJ. Effect of diclofenac, ketorolac, and fluorometholone on arachidonic acid metabolites following excimer laser corneal surgery. Arch Ophthalmol 1996; 114: 1495-1498.

22 Chen X, Gallar J, Belmonte C. Reduction by antiinflammatory drugs of the response of corneal sensory nerve fibers to chemical irritation. Invest Ophthalmol Vis Sci 1997; 38: 1944-1953.

23 Tomas-Barberan S, Fagerholm P. Influence of topical treatment on epithelial wound healing and pain in the early postoperative period following photorefractive keratectomy. Acta Ophthalmol Scand 1999; 77: 135-138.

24 Sher NA, Frantz JM, Talley A, Parker P, Lane SS, Ostrov C et al. Topical diclofenac in the treatment of ocular pain after excimer photorefractive keratectomy. Refract Cornea Surg 1993; 9: 425-436.

25 Congdon NG, Schein OD, von Kulajta P, Lubomski LH, Gilbert D, Katz J. Corneal complications associated with topical ophthalmic use of nonsteroidal antiinflammatory drugs. J Cataract Refract Surg 2001; 27(4): 622-631.

26 Shimazaki J, Saito H, Yang HY, Toda I, Fujishima H, Tsubota K. Persistent epithelial defect following penetrating keratoplasty: an adverse effect of diclofenac eyedrops. Cornea 1995; 14: 623-627.

27 Garcia-Hirschfeld J, Lopez-Briones LG, Belmonte C. Neurotrophic influences on corneal epithelial cells. Exp Eye Res 1994; 59: 597-605.

28 Dawson CR, Togni B. Herpes simplex eye infections: Clinical manifestations, pathogenesis and management. Surv Ophthalmol 1976; 21: 121-135.

29 Mackie IA. Role of the corneal nerves in destructive disease of the cornea. Trans Ophthalmol Soc UK 1978; 98: 343-347.

30 Sun R, Gimbel HV. Effects of topical ketorolac and diclofenac on normal corneal sensation. J Refract Surg 1997; 13: $158-161$. 